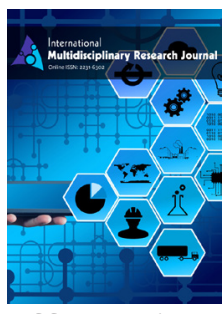

ISSN: 2231-6302

Received: January 30, 2019

Accepted: March 17, 2019

Published: March 20, 2019

*Corresponding Author:

Bilal Nawaz

Email: bajwauaf478@gmail.

com

\section{Genetic analysis of yield components and fiber quality parameters in upland cotton}

\author{
Bilal Nawaz*, Saira Sattar, Tanwir Ahmad Malik \\ Department of Plant Breeding and Genetics, University of Agriculture, Faisalabad-38040, Pakistan
}

\begin{abstract}
The experiment was laid to analyze genetic features, genotypic and phenotypic correlation coefficients, path analysis with regression analysis among yield contributing traits in a selected $\mathrm{F}_{3}$ populations of upland cotton including parents. In this research experiment ANOVA showed significant difference among all individual plants in $\mathrm{F}_{3}$ populations. Monopodia per plant and bolls per plant possessed maximum value of PCV\% and GCV\%. Maximum broad sense heritability $(\geq 90)$ was found in all recorded traits except seeds per boll, fiber length and lint percentage. Correlation studies revealed that Seed cotton yield positively correlated with all yield contributing traits i.e. plant height, monopodial branches per plant, Number of bolls per plant, boll weight, lint weight, seed index, lint index, seeds per boll, fiber fineness, fiber strength and fiber uniformity at both genotypic and phenotypic level whereas it depicted negative relationship with staple length. Path coefficient analysis showed that maximum direct positive effect was found of lint weight (2.6005) on seed cotton yield followed fiber fineness (1.2628), seed index (1.1449) and bolls per plant (1.0027). Regression study exhibited that maximum value of $\mathrm{R}^{2}$ for lint weight (0.9509) and boll weight (0.3735) depicted that $95.09 \%$ and $37.35 \%$ variation in the seed cotton yield, due to its relationship with lint weight and boll weight. It is concluded that there is a great genetic potential in $\mathrm{F}_{3}$ populations for mostly yield contributing traits for further enhancing yield. So those traits should be used as selection criteria during breeding for yield.
\end{abstract}

KEY WORDS: Genetic variability, correlation, path coefficient analysis, regression, upland cotton (Gossypium hirsutum L).

\section{INTRODUCTION}

In more than 60 countries, cotton is cultivated worldwide as an important fiber crop. Due to its importance commercially, cotton has significant role in Pakistan in improving national economy, and considered as "white Gold". The country ranks fourth in production of cotton. Cotton accounts for $5.1 \%$ to agriculture sector and $1 \%$ to GDP. The cropped area of cotton in Pakistan is 2.917 million hectares with the production of $587 \mathrm{~kg} / \mathrm{ha}$ in Pakistan. [10] studied that Excavations of Mohen Jo Daro exhibited that before 2500 B.C. cotton was grown in Sindh Pakistan. Cotton is often cross pollinated crop so large amount of variation for various traits was observed. Among the four species, G. hirsutum and G. barbadense are allotetraploid cotton species having appearance of large shrubs to small trees. The species G. barbadense is native to South America but spread to Caribbean and Mesoamerica. The center of diversity of G. hirsutum is Mesoamerica, but also found in the Caribbean, some Pacific Islands and northern South America. The species G. arboreum is Asiatic in origin and G. herbaceum is African in origin. The species G. hirsutum is called upland cotton which is grown on $90 \%$ of the cotton area in the world while is called
Egyptian cotton is used as name for G. barbadense grown on $9 \%$ area. The species G. arboreum and G. herbaceum are called desi cotton and are grown on $1 \%$ area of cotton cultivation in the world. Upland cotton is the most important cultivated species and is cultivated on more than $99 \%$ of the cotton grown areas in Pakistan. It is cultivated in the irrigated land of Sindh and Punjab and some parts of Baluchistan and K.P.K. The Pakistan's economy mainly depends on cotton and textile products. It provides livelihood to 1.5 million farming families [7].

Due to its importance, cotton crop has attracted the consideration of plant breeders and they have improved the cotton plant significantly. Through these efforts, there are high yielding cultivars by improving production potential and quality traits through breeding. Since genetic improvement process never ends; therefore, cotton breeders continue their efforts to evolve varieties with higher yield and better fiber quality. Seed cotton yield is a polygenic trait and depends on its components. These components may link or segregate independently, so to conduct a breeding program, study of genetic characteristics related to yield and fiber quality is important. A thorough knowledge of genetic variability, heritability, correlation, path

Copyright: () Nawaz, et al. This article is open access and licensed under the terms of the Creative Commons Attribution License (http://creativecommons.org/licenses/by/4.o/) which permits unrestricted, use, distribution and reproduction in any medium, or format for any purpose, even commercially provided the work is properly cited. Attribution - You must give appropriate credit, provide a link to the license, and indicate if changes were made. 
coefficient analysis and regression analysis and fiber quality characters is useful to develop high yielding cotton varieties with good fiber quality. So the present study was designed to find out GCV, PCV, heritability, correlation, path coefficient analysis and regression coefficients of seed cotton yield with other characters like plant height, number of sympodial branches per plant, number of monopodial branches per plan, bolls per plant, boll weight, lint weight, seed cotton yield, seed index, lint percentage, lint index, seeds per boll, fiber fineness, fiber strength, fiber length and fiber uniformity. This information will be useful for cotton breeders to improve seed cotton yield and quality in cotton varieties.

\section{MATERIALS AND METHODS}

The experiment was laid out in the experimental area of the Department of Plant Breeding and Genetics, University of Agriculture Faisalabad during 2015-2017. Breeding material consisted of two parents (CRS-456 and Jambo-Okra) and 75 selected $\mathrm{F}_{2}$ progeny of their parents. The experiment was designed in randomized complete block design (RCBD) having 3 replications in the field during normal sowing season. In each row there were 10 plants. Row to row and plant to plant distance was maintained $75 \mathrm{~cm}$ and $30 \mathrm{~cm}$ respectively. All kinds of recommended crop cultural practices from seed sowing to seed cotton picking were provided. At maturity, 25 plants of $\mathrm{F}_{3}$ population and 5 plants from each parent were selected at random from each replication. Data on various traits (Plant height, number of sympodial branches per plant, number of monopodial branches per plant, bolls per plant, boll weight, lint weight, seed cotton yield, seed index, lint percentage, lint index, seeds per boll, fiber fineness, fiber strength, fiber length and fiber uniformity) were recorded.

\section{Statistical Analysis}

The analysis of variance (ANOVA) was applied to check genetic variation of the experiment's data [29]. Genotypic and Phenotypic correlation were calculated though the statistical technique prescribed by Kowon and Terrie [16]. By using the method of [17], significance of genotypic correlations were checked. Statistical significance of phenotypic correlation was tested by T-test as described by Steel and Terrie [30]. Path coefficient analysis was performed by using the method prescribed by Dewey and Lu [5]. Regression coefficient of seed cotton yield with various agronomic traits was also studied. $R^{2}$ reveals the dependency of $Y$ (dependable variable) on $X$ (independent variable), while regression intercept $(\beta 0)$ determines yield of dependable variable without using any amount of independent variable and regression slop $(\beta 1)$ exhibits change in dependable variable with one unit change in independent variable.

\section{RESULT AND DISCUSSION}

It was clear from Tablel that significant differences were present between all genotypes for all yield contributing traits because analysis of variance all traits showed significance value of mean squares. Basically effectiveness of selection totally depends upon presence of magnitude of genetic variability because it facilitates plant breeders in selection program. The mean values and standard error for all traits are given in Table 1.

\section{Genetic Variability and Heritability Study}

Genetic variability for all the traits are given in Table 1. Genetic variability is important in breeding program [28]. The trait plant height exhibits the highest GV and PV i.e. 135.38 and 135.68 respectively followed by bolls per plant that have GV 93.543 and PV 93.989. Lowest GV 0.0061, 0.366, 0.0011, 1.007 and PV $0.0064,0.368,0.0033,1.008$ was measured for the traits of boll weight, fiber fineness, and fiber length and seed index. Ahsan et al. [1] also reported same results that boll weight and seed index had lowest genotypic and phenotypic variance while seed cotton yield and plant height possessed highest GV and PV. Due to environmental effects on expression of traits, there should be separation between genetic and phenotypic variances to perform efficient selection [18]. The Genotypic, Phenotypic and Environment coefficient of variances were also depicted for all studied traits under. The GCV was ranged from $51.521 \%$ (monopodial branches per plant) to $0.126 \%$ (fiber length). Maximum GCV was found for monopodial branches per plant $(51.521 \%)$ followed by bolls per plant $(24.190 \%)$. Mendez-Natera et al., [18] reported similar results that PCV\% was possessed high magnitude as compared to GCV\% for all the recorded traits.

Due to a close correspondence between GCV and PCV, PCV showed similar trend as GCV for all the traits under study. Result revealed that in phenotypic expression, all recorded traits exhibited less environment effect. As coefficient of variation has not effect on the measuring units. Hence it plays a significant role in comparing population because variation linked with magnitude of the measuring units. The highest GCV and PCV for the traits like monopodial branches per plant, bolls per plant, sympodial branches per plant and lint weight shows that selection can be performed on the characters to separate promising line.

The traits such as fiber length, boll weight, fiber uniformity, fiber strength and lint percentage showed low GCV and PCV which revealed that breeders should find out new sources containing high genetic variability for these characters to make more genetic enhancement. There are three main factors i.e. genetics, environmental factors and their interactions that resulted of total variation in a population. Heritability which measures index of transmission of genetic variability. Those traits that contain high value of genetic advance and heritability estimates, in early generation that exhibited that these traits possessed additive gene action under less environmental effects [22]. Results in Table 1 showed that all traits possessed highest value of broad sense heritability estimates except fiber length, seeds per boll and lint percentage under study. These results was in accordance with Ravikesavan [26] and Hussain et al. [7], and Vineela et al. [32] whom recorded additive gene action for bolls per plant, plant height and seed cotton yield due 
Table 1: Genetic components for various yield related traits in $\mathrm{F}_{3}$ populations of the cross CRS-456 $\times$ Jambo-0kra in upland cotton

\begin{tabular}{|c|c|c|c|c|c|c|c|c|c|c|c|}
\hline Traits & MS & Grand mean \pm S.E & $\begin{array}{l}\text { Genotypic } \\
\text { variance }\end{array}$ & $\begin{array}{l}\text { Genotypic } \\
\text { coefficient of } \\
\text { variance \% }\end{array}$ & $\begin{array}{l}\text { Phenotypic } \\
\text { variance }\end{array}$ & $\begin{array}{l}\text { Phenotypic } \\
\text { coefficient of } \\
\text { variance \% }\end{array}$ & $\begin{array}{l}\text { Environmental } \\
\text { variance }\end{array}$ & $\begin{array}{c}\text { Environmental } \\
\text { coefficient of } \\
\text { variance } \%\end{array}$ & $\begin{array}{c}\text { Heritability } \\
\mathrm{h}_{2} \mathrm{bs} \%\end{array}$ & $\begin{array}{l}\text { Genetic } \\
\text { advance }\end{array}$ & $\begin{array}{c}\text { Genetic } \\
\text { advance of } \\
\text { mean (\%) }\end{array}$ \\
\hline $\mathrm{PH}$ & $14.72^{*}$ & $106.59+0.32$ & 135.38 & 10.92 & 135.68 & 10.93 & 0.3 & 0.51 & 99.78 & 23.94 & 22.46 \\
\hline SB & $8.47^{*}$ & $11.44+0.35$ & 6.11 & 21.60 & 6.47 & 22.22 & 0.35 & 5.17 & 94.48 & 4.95 & 43.25 \\
\hline MP & $4.46 * *$ & $5.21+0.36$ & 7.22 & 51.521 & 7.6005 & 52.8703 & 0.3805 & 11.84 & 94.96 & 5.393 & 103.423 \\
\hline BPP & $243.47 * *$ & $39.983+0.386$ & 93.543 & 24.190 & 93.989 & 24.247 & 0.446 & 1.67 & 99.525 & 19.877 & 49.712 \\
\hline BW & $0.229 * *$ & $2.263+0.0094$ & 0.0061 & 3.448 & 0.0064 & 3.522 & 0.0003 & 0.765 & 95.804 & 0.157 & 6.952 \\
\hline LW & $212.78^{*}$ & $21.729+0.416$ & 13.264 & 16.761 & 13.783 & 17.085 & 0.519 & 3.315 & 96.237 & 7.360 & 33.872 \\
\hline SCY & $893.43 * *$ & $50.734+0.496$ & 63.811 & 15.745 & 64.547 & 15.836 & 0.736 & 1.69 & 98.859 & 16.361 & 32.249 \\
\hline SI & $0.561 * *$ & $7.240+0.015$ & 1.007 & 13.859 & 1.008 & 13.864 & 0.001 & 0.437 & 99.934 & 2.066 & 28.540 \\
\hline LP & $6.48 * *$ & $41.202+0.811$ & 6.091 & 5.990 & 8.063 & 6.892 & 1.972 & 3.408 & 75.540 & 4.419 & 10.724 \\
\hline LI & $4.36 * *$ & $18.35+0.316$ & 8.543 & 15.928 & 8.842 & 16.205 & 0.299 & 2.980 & 96.618 & 5.918 & 32.253 \\
\hline SPB & $7.83 * *$ & $18.662+0.759$ & 2.609 & 8.655 & 4.337 & 11.160 & 1.728 & 7.044 & 60.149 & 2.581 & 13.828 \\
\hline FF & $1.40 * *$ & $5.579+0.029$ & 0.366 & 10.837 & 0.368 & 10.874 & 0.002 & 0.802 & 99.313 & 1.241 & 22.247 \\
\hline FS & $0.79 * *$ & $29.390+0.030$ & 2.513 & 5.394 & 2.516 & 5.397 & 0.003 & 0.186 & 99.894 & 3.264 & 11.106 \\
\hline $\mathrm{FL}$ & $3.21 * *$ & $26.827+0.027$ & 0.0011 & 0.126 & 0.0033 & 0.215 & 0.0022 & 0.175 & 34.499 & 0.041 & 0.153 \\
\hline FU & $5.32 * *$ & $49.423+0.035$ & 6.928 & 5.326 & 6.932 & 5.327 & 0.004 & 0.128 & 99.948 & 5.421 & 10.968 \\
\hline
\end{tabular}

$* *=p \leq 0.01, *=p \leq 0.05$, PH: Plant height, SB: Sympodial branches per plant, MB: Monopodial branches per plant, BPP: Bolls per plant, BW: Boll weight, LW: Lint weight, SCY: Seed cotton yield, SI: Seed index, LP: Lint percentage, LI: Lint index, SPB: Seeds per boll, FF: Fiber fineness, FS: Fiber strength, FL: Fiber length, FU: Fiber uniformity, MS: Mean sun of square, SE: Standard error

to high heritability. To obtain more reliability of desired traits through efficient selection, heritability solely is not sufficient rather combination of both heritability and genetic advance are obligatory. The genetic advance ranged from $0.153 \%$ to $103.423 \%$. Highest genetic advance as percentage of mean was recorded by monopodial branches per plant (103.423) followed by the bolls per plant (49.712), sympodial branches per plant (43.25), lint weight (33.872), lint index (32.253), seed cotton yield (32.249), seed index (28.540), plant height (22.46), fiber fineness (22.247), seeds per boll (13.828) fiber strength (11.106), fiber uniformity (10.968), lint percentage (10.724), boll weight (6.952) and fiber length $(0.153)$. So from the outcome of the current study, it can be determined that those yield contributing traits that possessed high heritability and genetic advance can be improved through direct selection. As high value of GCV and PCV for studied traits indicated that that influences of environment on these traits are very minor. So it is concluded that the traits which have high values of genetic advance may be improved by selection in early generation.

\section{Correlation studies}

Correlation among all yield related traits at both genotypic and phenotypic level are given in Table 2 . In this study, genotypic correlation $\left(\mathrm{r}_{\mathrm{g}}\right)$ showed same trend as phenotypic correlation $\left(\mathrm{r}_{\mathrm{p}}\right)$ but in most cases $r_{g}$ possessed a greater value than $r_{p}$ that reveals that genetic causes were more in expression of those traits than environmental causes. Irum et al. [9] stated that presence of adequate genetic variation gives strength of relationship among various yield contributing traits.

Seed cotton yield depicted positive link with all yield related traits i.e. plant height, monopodia per plant, bolls per plant, boll weight, lint weight, seed index, lint index, seeds per boll, fiber fineness, fiber strength and fiber uniformity at both genotypic and phenotypic level while it exhibited negative relationship with staple length. It showed non-significant relationship with sympodia per plant and lint percentage. It was also noticed that monopodial branches per plant, bolls per plant, lint weight, seed index, lint index and seeds per boll contributed more variation to seed cotton yield as compared to other traits. Ashokkumar and Ravikesavan [3] reported similar results that seed cotton yield depicted positive genotypic and phenotypic association with plant height, bolls per plant, boll weight, fiber strength. All fiber quality traits can be improved with increasing seed cotton yield except fiber length. Same result was found by the previous findings that seed cotton yield had negative association with fiber length at both genotypic and phenotypic level (Meredith, [22] Ulloa, [31] Zeng and Meredith [33] Hinze et al., [6]. Naveed et al. [21] reported that plant height is having positive correlation with seed cotton yield at both levels. Killi et al. [13] also observed positive correlation of seed cotton yield with plant height. [5] studied that seed cotton yield showed positive linkage with boll weight. Khan et al. [11] reported same information that plant height, bolls per plant and boll weight depicted positive association with seed cotton yield. Rao and Gopinath [24] also observed that number of bolls per plant, number of monopodia per plant, seed index and plant height had significant positive correlated with seed cotton yield per plant. So correlation study conclude that those traits which depicted positive link with seed cotton yield should be kept into mind while breeding diverse genotypes of upland cotton towards yield.

\section{Path coefficient analysis}

The effect of independent trait on the dependent is called as direct effect. The Path Coefficients analysis enables breeder to focus on the variable which show high direct effect on seed cotton yield.

The genotypic correlation coefficient of seed cotton yield with other yield contributing traits and fiber quality characters were further partitioned into direct and indirect effects (Table 3). 
Nawaz, et al.

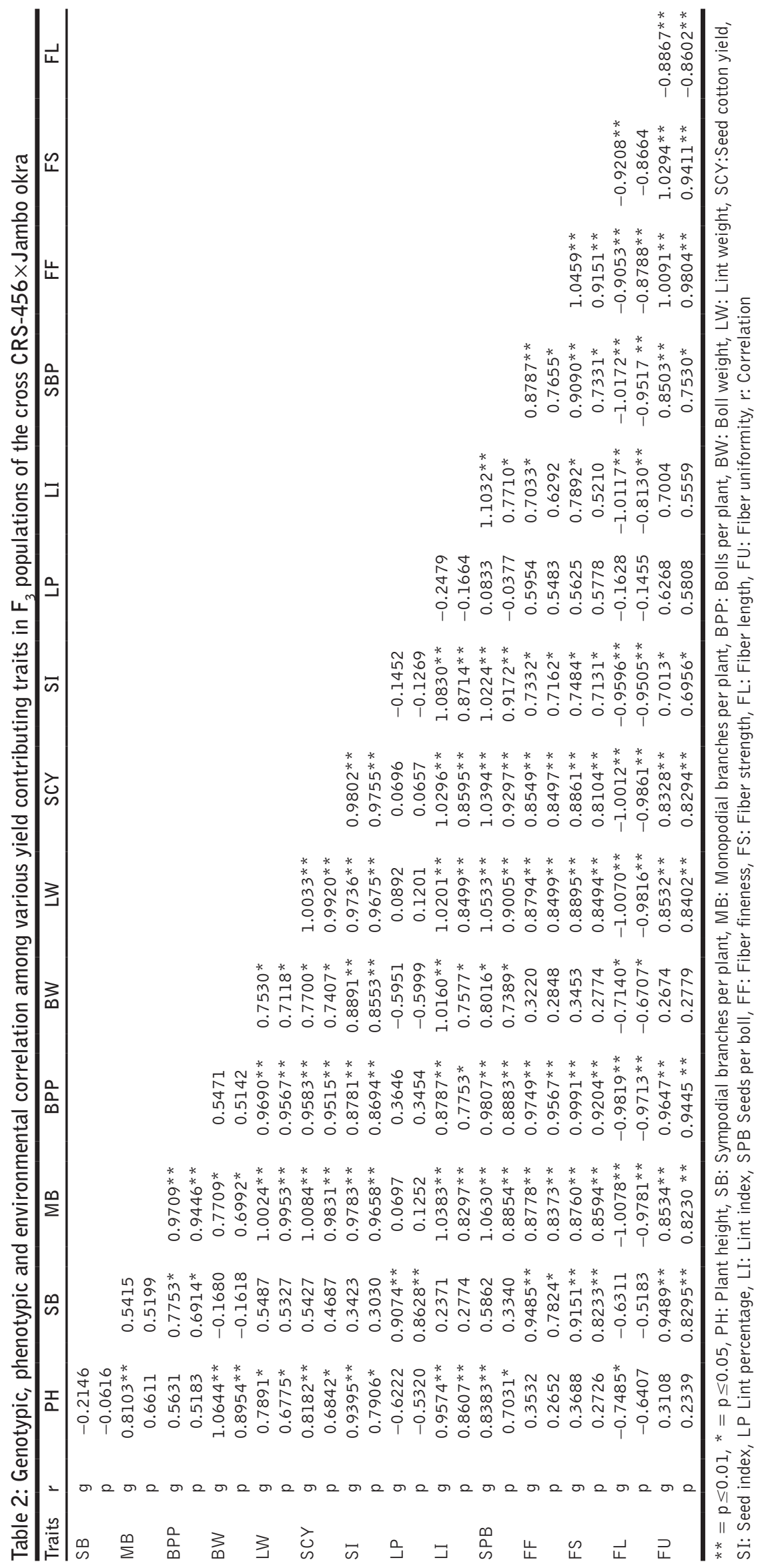

16

Int Multidiscip Res J • 2019 • Vol 9 
Table 3: Direct (diagonal) and indirect (off-diagonal) effects of various traits in upland cotton

\begin{tabular}{|c|c|c|c|c|c|c|c|c|c|c|c|c|c|c|}
\hline & $\mathrm{PH}$ & SB & $\mathrm{MB}$ & BPP & BW & LW & SI & LP & LI & SPB & FF & FS & $\mathrm{FL}$ & FU \\
\hline $\mathrm{PH}$ & 0.4514 & -0.1874 & -4.1973 & 0.5646 & 0.0111 & 2.0521 & 1.0974 & 0.1894 & -1.1653 & 0.1096 & 0.5076 & 0.0337 & -0.5644 & 0.2466 \\
\hline SB & -0.0969 & 0.8734 & -2.8048 & 0.7775 & -0.0017 & 1.4269 & 0.3998 & -0.2763 & -0.2886 & 0.0766 & 1.3631 & 0.0837 & -0.4759 & 0.9146 \\
\hline MB & 0.3658 & 0.4729 & -5.1799 & 0.9735 & 0.0080 & 2.6066 & 1.1427 & -0.0212 & -1.2638 & 0.1389 & 1.2614 & 0.0801 & -0.7600 & 0.7754 \\
\hline BPP & 0.2542 & 0.6772 & -5.0290 & 1.0027 & 0.0057 & 2.5199 & 1.0256 & -0.1110 & -1.0696 & 0.1282 & 1.4009 & 0.0914 & -0.7404 & 0.8931 \\
\hline BW & 0.4804 & -0.1468 & -3.9930 & 0.5486 & 0.0104 & 1.9581 & 1.0385 & 0.1812 & -1.2368 & 0.1048 & 0.4627 & 0.0316 & -0.5384 & 0.2024 \\
\hline LW & 0.3562 & 0.4792 & -5.1921 & 0.9717 & 0.0078 & 2.6005 & 1.1372 & -0.0272 & -1.2418 & 0.1377 & 1.2637 & 0.0814 & -0.7593 & 0.7756 \\
\hline SI & 0.3693 & 0.4739 & -5.2232 & 0.9609 & 0.0080 & 2.6091 & 1.1449 & -0.0212 & -1.2533 & 0.1358 & 1.2285 & 0.0811 & -0.7549 & 0.7546 \\
\hline LP & 0.4241 & 0.2990 & -5.0677 & 0.8805 & 0.0093 & 2.5318 & 1.1680 & 0.0442 & -1.3183 & 0.13 & 1.0536 & 0.0685 & -0.7236 & 0.6236 \\
\hline LI & -0.2809 & 0.7925 & -0.3611 & 0.3656 & -0.0062 & 0.2320 & -0.1696 & -0.3045 & 0.3018 & 0.0109 & 0.8557 & 0.0515 & -0.1228 & 0.6290 \\
\hline SPB & 0.4321 & -5.3780 & -5.3780 & 0.8811 & 0.0106 & 2.6528 & 1.2650 & 0.0755 & -1.2173 & 0.1442 & 1.0107 & 0.0722 & -0.7629 & 0.6188 \\
\hline FF & 0.3784 & 0.5120 & -5.5064 & 0.9833 & 0.0083 & 2.7391 & 1.1941 & -0.0254 & -1.3428 & 0.1307 & 1.2628 & 0.0832 & -0.7670 & 0.7720 \\
\hline FS & 0.1594 & 0.8284 & -4.5468 & 0.9775 & 0.0034 & 2.2868 & 0.8564 & -0.1813 & -0.8561 & 0.1148 & 1.4370 & 0.0957 & -0.6826 & 0.9454 \\
\hline $\mathrm{FL}$ & 0.1665 & 0.7992 & -4.5375 & 1.0018 & 0.0036 & 2.3132 & 0.8741 & -0.1713 & -0.9607 & 0.1188 & 1.5031 & 0.0915 & -0.6943 & 0.9663 \\
\hline FU & -0.3379 & -0.5512 & 5.2205 & -0.9846 & -0.0074 & -2.6186 & -1.1208 & 0.0496 & 1.2315 & -0.1329 & -1.3010 & -0.0842 & 0.7541 & -0.8106 \\
\hline
\end{tabular}

RESIDUE $=0.2478$

** $=p \leq 0.01, *=p \leq 0.05$, PH: Plant height, SB: Sympodial branches per plant, MB: Monopodial branches per plant, BPP: Bolls per plant,

BW: Boll weight, LW: Lint weight, SCY: Seed cotton yield, SI: Seed index, LP: Lint percentage, LI: Lint index, SPB: Seeds per boll, FF: Fiber fineness, FS: Fiber strength, FL: Fiber length, FU: Fiber uniformity

Table 4: Regression coefficient between seed cotton yield and its contributing traits of upland cotton during 2017

\begin{tabular}{lccc}
\hline Parameters & \multicolumn{3}{c}{ Regression coefficients } \\
\cline { 2 - 4 } & $\mathrm{R}^{2}$ & Slope $(\beta 1)$ & Intercept $(\beta 0)$ \\
\hline Plant height & 0.02332 & 0.4106 & 25.43 \\
Sympodial branches per plant & 0.06922 & 2.79 & 35.67 \\
Monopodial branches per plant & 0.006001 & 1.03 & 60.55 \\
Bolls per plant & 0.035 & 0.4305 & 52.16 \\
Boll weight & 0.3735 & 10.66 & 34.79 \\
Lint weight & 0.9509 & 2.293 & 3.252 \\
Seed index & 0.02506 & 5.347 & 31.93 \\
Lint percentage & 0.1417 & 2.306 & -30.07 \\
Lint index & 0.03894 & 1.022 & 49.52 \\
Seeds per boll & 0.1311 & 0.7315 & 47.75 \\
Fiber fineness & 0.1821 & 22.68 & -32.04 \\
Fiber strength & 0.1772 & 10.38 & -213.1 \\
Fiber length & 0.1872 & 9.484 & -186.4 \\
Fiber uniformity & 0.1639 & 6.609 & -254.4 \\
\hline
\end{tabular}

$\mathrm{R}^{2}=$ Regression coefficient of determination

The component of residual effect in path coefficient analysis in seed cotton yield and fiber quality traits was 0.2478 . The low residual effect revealed that the traits selected for path coefficient analysis were adequate and appropriate. The result revealed that all traits influenced directly and positively on except monopodia per plant, fiber length and fiber uniformity. Maximum direct effect on seed cotton yield was found for traits like lint weight (2.6005), fiber fineness (1.2628), seed index (1.1449) and bolls per plant (1.0027). It is suggested on basis of path coefficient analysis that emphasis should be given to lint weight, fiber fineness, seed index and bolls per plant for increasing in seed cotton yield. [18] observed similar result from the study of path coefficient analysis that monopodia per plant exhibited negative link with seed cotton yield. Iqbal et al. [8] also found that fiber length had negative direct effect on seed cotton yield. Chitti et al. [4], Krishna Mohan [14], Rajanna et al. [23], Kumari Vinodhana et al. [15] and Rumesh Ranjan et al. [27] also found positive direct effect of bolls per plant, boll weight and seed index on seed cotton yield at both genotypic and phenotypic level.

\section{Regression analysis}

Regression analysis is used to check dependence of dependent variable on independent variable. It basically measures how much change will be occur in dependent variable by changing (increasing or decreasing) one unit in independent variable. Regression coefficient of determination $\left(\mathrm{R}^{2}\right)$ and regression coefficients $(\beta 0, \beta 1)$ for all traits were given in Table 4. Graphical representation for dependency of seed cotton yield on various yield related traits was given in Figure 1(a-n). Result showed that maximum value of coefficient of determination was found for lint weight $(0.9509)$ followed by boll weight $(0.3735)$ while lowest value of $\mathrm{R}^{2}$ exhibited by monopodial branches per plant (0.006001) followed by plant height (0.02332). Maximum value of $\mathrm{R}^{2}$ for lint weight and boll weight depicted that $95.09 \%$ and $37.35 \%$ change (increase or decrease) in seed cotton yield (dependent variable) was occurred with one unit changing (increasing or decreasing) in lint weight and boll weight (dependent variables). Remaining change in seed cotton yield was occurred due other environmental factors not due to lint weigh and boll weight. Regression coefficient $(\beta 1)$ ranged from 22.68 (fiber fineness) to 0.4106 (plant height) respectively. It indicated that for a unit increase in fiber fineness and plant height, there would be a proportional of $22.68 \mathrm{~g}$ and $0.4106 \mathrm{~g}$ in seed cotton yield. Regression intercept $(\beta 0)$ ranged from 60.55 (monopodial branches per plant) to -254.4 (fiber uniformity) respectively. Result of regression intercept revealed that seed cotton yield was $60.55 \mathrm{~g}$ without using any unit of independent variable. The finding observed by the author in present research work are in agreement to the results found by Ansari et al., [2] and Killi [12].

\section{CONCLUSIONS}

The highest GCV and PCV for the traits monopodia and sympodia per plant, bolls per plant, and lint weight shows that selection can be performed on the traits to isolate promising line. All traits possessed high heritability estimates except fiber length, GOT\% and seeds per boll. Selection can be performed 

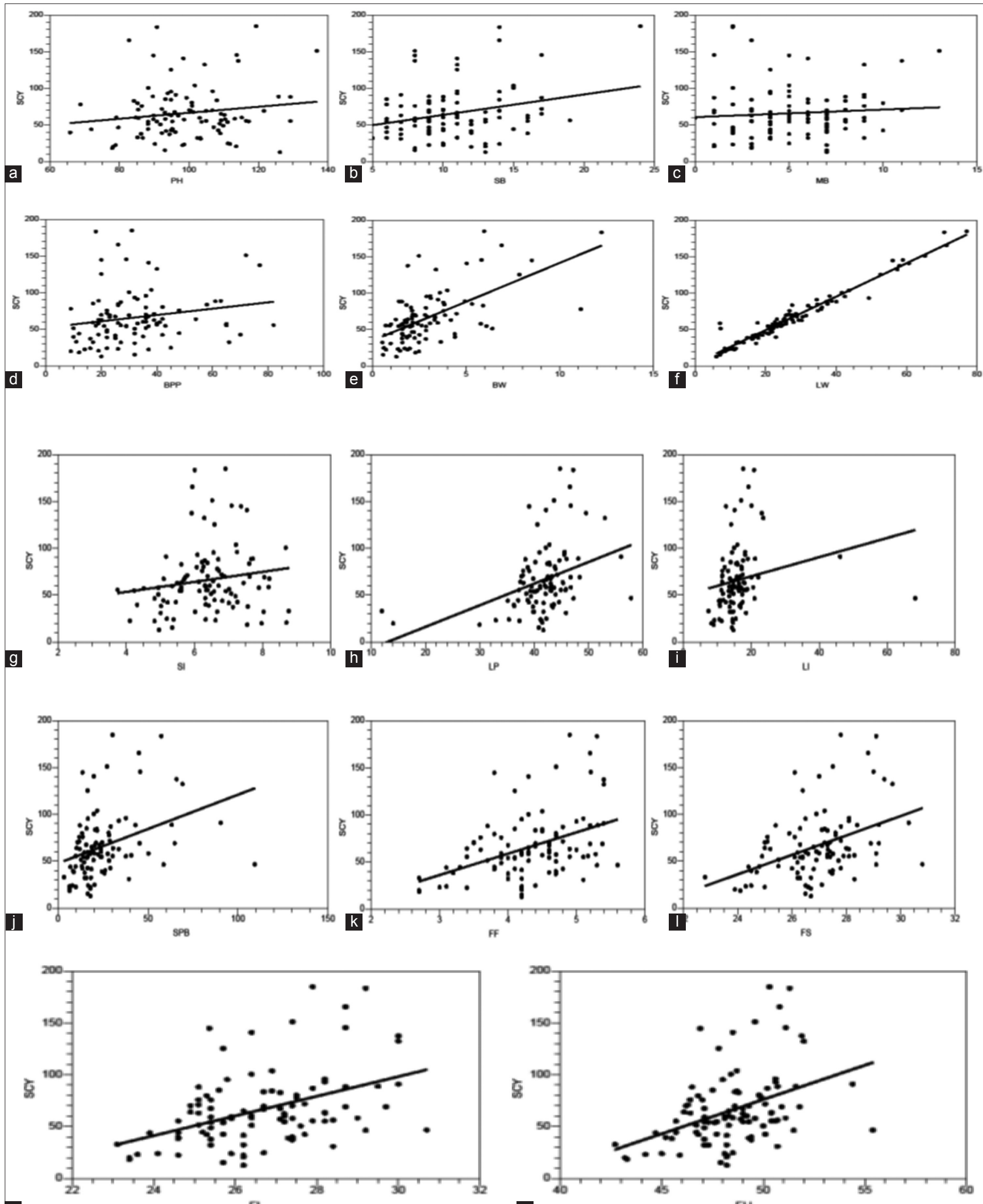

m

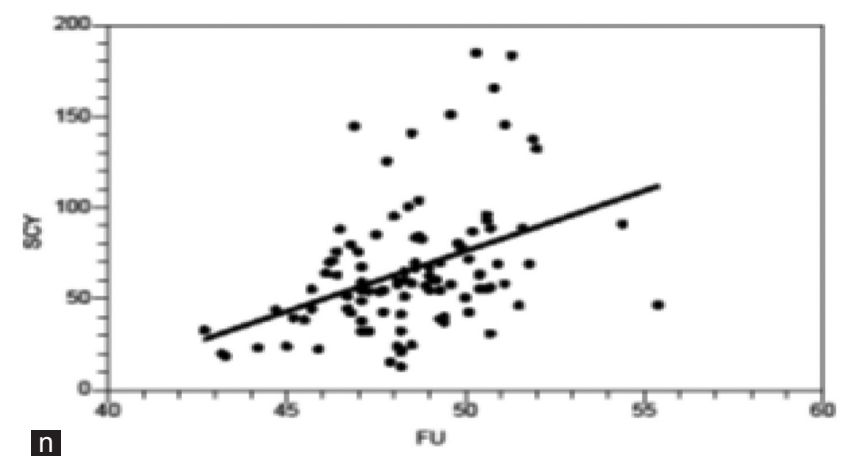

Figure 1: (a-n) Graphical presentation of mean values of traits

for those yield related traits in early generation that possess maximum value heritability estimates and genetic advance. Seed cotton yield depicted positively link with all yield contributing traits i.e. plant height, monopodia per plant, bolls per plant, boll weight, lint weight, seed index, lint index, seeds per boll, fiber fineness, fiber strength and fiber uniformity at 
both genotypic and phenotypic level while it possessed negative relationship with fiber length. Maximum direct effect was found for lint weight, fiber fineness, seed index, bolls per plant, and seeds per boll and plant height. It is suggested on basis of path coefficient analysis that emphasis should be given to plant height, seeds per boll, bolls per plant, lint weight, seed index and fiber fineness for increasing in seed cotton yield. Seed cotton yield also showed strong and positive dependency on lint weight and boll weight. Thus during future breeding programme these parameters also kept in mind during making selection as they were the major attributes of the seed cotton yield.

\section{REFERENCES}

1. Ahuja, S.L., Dhayal, L.S. and Parkash, R. A correlation and path coefficient analysis of components in Gossypium hirsutum L. hybrids by usual and fibre quality grouping. Turk. J. Agric. 2006; 30:317-324.

2. Ansari, A.H., Malik, M.A., Qayyum, S.M., and Ansari, N.N. Phenotypic correlation and regression analysis in cotton (Gossypium hirsutum L.), cv. TH-1174. J. Agric. Res. Lahore, 1989; 27(2): 89-93.

3. Ashokkumar and Ravikesavan R. Genetic Studies of Correlation and Path Coefficient analysis for seed oil, yield and Fibre quality traits in Cotton (G. hirsutum L.) Aust. J. Basic. Appl. Sci. 2010; 4(11): 5496-5499.

4. Chitti, B. K., Rajesh, S.P., Katageri, I.S., Sekhar, L. and Khadi, B.M. Direct and indirect effect of various traits on seed cotton yield in single, double- and three-way cross derivatives in upland cotton (Gossypium arboreum L.). Journal of Cotton Research and Development. 2014; 28(2): 195- 200.

5. Dewey, D.R. and Lu, K.H. A correlation and path coefficient analysis of components of crested wheat grass seed production. Agron. J. 1959: 51: 515- 518

6. Hinze, L.L., Campbell, B.T. and Kohel. R.J. Performance and combining ability in cotton (Gossypium hirsutum L.) populations with diverse parents. Euphytica, 2011; 181: 115-125.

7. Hussain, S., Nawab, N.N., Ali, M.A., Hussain, A., Nawaz, M.A. and Malik, T.A. Evolution of performance, genetic divergence and character association of some polygenic traits in upland cotton. J. Agric. Soc. Sci. 2010, 6(4): 79-82

8. Iqbal, M., Chang, M.A., Iqbal, M.Z., Hassan, M.U., Nasir, A. and Islam, N.U. Correlation and path coefficient analysis of earliness and agronomic characters of upland cotton in Multan. Pak. J. Agron. 2003, 2: $160-168$.

9. Irum, A., Tabasum, A. and Iqbal, M.Z. Variability, correlation and path coefficient analysis of seedling traits and yield in cotton (Gossypium hirsutum. L.). African Journal of Biotechnology. 2011, 10(79):1810418110.

10. Khan, N. U. Genetic analysis, combining ability and heterotic studies for yield, its components, fibre and oil quality traits in upland cotton (G. hirsutum) (Ph.D. Dissertation). Sindh Agric. Univ. Tandojam, Pakistan, 2003.

11. Khan, N.U., Marwat, K.B., Hasssan, G., Kumbhar, M.B., Farhatullah, Soomro, Z.A., Khan, N., Parveen, A. and Aiaman, U. Study of fiber quality traits in upland cotton using additive-dominance model. Pak. J. Bot. 2009, 41: 1271-1283.

12. Killi, F. Path coefficient analysis and correlations for cotton (Gossypium hirsutum L.) yield and some yield components in the East Mediterranean and GAP (Southeastern Anatolian Project) regions. Turkish J. Agric. \& Forestory. 1995, 19(5): 379-382.

13. Killi, F., Efe, L. and Mustafayev, S. Genetic and environmental variability in yield, yield components and lint quality traits of cotton.
Int. J. Agri. Biol., 2005, 7(6): 1007-1010.

14. Krishna Mohan, M. Combining ability analysis for fibre quality in interspecific hybrids of cotton. M.Sc. (Ag) Thesis. Acharya N G Ranga Agricultural University, Hyderabad, India, 2011.

15. Kumari Vinodhana, N., Gunasekaran, M. and Vindhyavarman, P. Genetic studies of variability, correlation and path coefficient analysis in cotton genotypes. International Journal of Pure and Applied Bioscience. 2013, 1(5): 6-10.

16. Kwon, S.H. and Torrie, J.H. Heritability and interrelationship among traits of two soybean population. Crop Sci. 1964, 4: 196-8.

17. Lotherop, J.E., Akins, R.E., Smith, O.S. Variability of yield and yield components in IAPIR grain sorghum random mating population means variance components and heritabilities. Crop Sci. 1985, 25:235-240.

18. Mahalingam, A., R. Saraswathi, J. Ramalingam and T. Jayaraj. Genetics of floral traits in cytoplasmic male sterile (CMS) and restorer lines of hybrid rice (Oryza sativa L.). Pak. J. Bot., 2013, 45(6): 1897-1904.

19. Méndez-Natera, J.R., A. Rondón, J. Hernández and J.F. Merazo-Pinto. Genetic studies in upland cotton. III. Genetic parameters, correlation and path analysis. Sabrao. J. Breeding \& Genetics, 2012, 44(1): $112-128$

20. Meredith, W.R. Quantitative genetics. In: Cotton. (Eds.): Kohel, R.J. and C.F. Lewis. ASA, CSSA, and SSSA, Madison, WI. 1984, pp. 131-150.

21. Naveed, M., F.M. Azhar and A. Ali. Estimates of heritabilities and correlations among seed cotton yield and its components in Gossypium hirsutum L. Int. J. Agri. Biol. 2004, 6(4): 712-714.

22. Panes, V. G., \& Sukhatme, P. V. Statistical methods for agricultural workers (3rd ed., p. 58). ICAR, New Delhi. 1995.

23. Rajanna, B., Samba Murthy, J.S.V., Lal Ahamed, M. and Srinivasa Rao, V. Correlation and path coefficient analysis in upland cotton (Gossypium hirsutum L.). The Andhra Agricultural Journal. 2011, 58(2): 151-155

24. Rao, P.J.M and M. Gopinath. Association analysis of yield and fiber quality characters in upland cotton (Gossypium hirsutum L.). Aust. J. Basic Appl. Sci. 2013, 7: 789-790.

25. Rauf, S., T.M. Khan, H.A. Sadaqat and A.L. Khan. Correlation and path coefficient analysis of yield components in cotton (Gossypium hirsutum L.). Int. J. Agric. Biol. 2004, 6: 686-688.

26. Ravikesavan, R. and K. Iyanar. Genetic advance and heritability as a selection index for improvement of yield and quality in cotton. J. Cotton Res. Dev. 2008, 22(1):14-18.

27. Rumesh Ranjan., R.S. Sangwan, S.S. Siwach, O. Sangwanand, M.K. Sah. Correlation and path analysis studies in Gossypium arboreum L. Journal of Cotton Research and Development. 2014, 28(1): 37-39.

28. Saleem, S., M. Kashif, M. Hussain, A.S. Khan and M.F. Saleem. Genetic behavior of morpho-physiological traits and their role for breeding drought tolerant wheat. Pak. J. Bot. 2016, 48(3): 925-933.

29. Steel, R. G. D., Torrie, J. H., \& Dicky, D. A. Principles and procedures of Statistics. A Biometrical Approach (3 ${ }^{\text {rd }}$ ed., pp. 400-428). New York: McGraw Hill Book Co. Inc. 1997.

30. Steel, R.D.G and Torrie, J.H. Principles and Procedures of Statistics -A Biometric Approach. McGraw Hill Book Co. Inc. New York, USA.

31. Ulloa, M. Heritability and correlations of agronomic and fiber traits in an okra-leaf upland cotton population. Crop Sci. 2006, 1984, 46: 15081514.

32. Vineela, N., Samba Murthy, J. S. V., Ramakumar, P. V., \& Ratna, K. S. Variability Studies for Physio Morphological and Yield Components Traits in American Cotton (Gossypium hirsutum L.). J. Agric. Vet. Sci. 2013, 4(3), 7-10.

33. Zeng, L. and Meredith, W.R. Associations among lint yield, yield components, and fiber 33. properties in an introgressed population of cotton. Crop Sci. 2009, 49: 1647-1654. 